\title{
Determinants of pelvic organ prolapse among gynecologic patients in Bahir Dar, North West Ethiopia: a case-control study
}

This article was published in the following Dove Press journal:

International Journal of Women's Health

I 2 December 2016

Number of times this article has been viewed

\section{Ayalnesh Asresie \\ Eleni Admassu ${ }^{2}$ \\ Tesfaye Setegn ${ }^{2}$}

'Hamlin Fistula Center, Amhara National Regional State, Bahir Dar, Ethiopia; ${ }^{2}$ Bahir Dar University, College of Medicine and Health Sciences, School of Public Health, Reproductive Health Department, Amhara National Regional State, Bahir Dar, Ethiopia
Correspondence: Tesfaye Setegn Department of Reproductive Health, School of Public Health, College of Medicine and Health Sciences, Bahir Dar University, PO Box 1977, Amhara National Regional State, Bahir Dar, Ethiopia Email tesfayesetegn@yahoo.com
Introduction: Pelvic organ prolapse (POP) is a significant public health problem in developing countries including Ethiopia. However, less has been documented on risk factors of POP. Therefore, the aim of this study was to identify the determinants factors of POP.

Methods: An unmatched case-control study was conducted among gynecologic patients in Bahir Dar city, North West Ethiopia, from July to October 2014. A total of 370 women (selected from outpatient departments) were included in the study. Cases (clients with stage III or IV POP) and controls (who declared free of any stages of POP) were identified by physicians using the Pelvic Organ Prolapse Quantitative Examination tool. Data analysis was carried out by SPSS version 20.0. Descriptive, bivariate, and multivariable logistic regression analyses were performed. Statistical differences were considered at $P<0.05$, and the strength of association was assessed by odds ratio (OR) and respective confidence intervals (CIs).

Results: This study revealed that determinants such as age of women ( $>40$ years) (adjusted $\mathrm{OR}[\mathrm{AOR}]=3.0$ [95\% CI: 1.59-5.89]), sphincter damage (AOR =8.1 [95\% CI: 1.67-39.7]), family history of POP (AOR $=4.9$ [95\% CI: 1.94-12.63]), parity $(\geq 4)$ (AOR $=4.5[95 \% \mathrm{CI}$ : 2.26-9.10]), nonattendance of formal education ( $\mathrm{AOR}=4.3$ [95\% CI: $1.25-14.8]$ ), carrying heavy objects (AOR $=3.1$ [95\% CI: 1.56-6.30]), body mass index $(\mathrm{BMI})<18.5 \mathrm{~kg} / \mathrm{m}^{2}$ (AOR $=3.1$ [95\% CI: $1.22-7.82]$ ), and delivery assisted by nonhealth professionals (AOR $=2.6[95 \%$ CI: 1.24-5.56]) were significantly associated with POP.

Conclusion: In our study, sphincter damage, family history of POP, being uneducated, having $\geq 4$ vaginal deliveries, carrying heavy objects, BMI $<18.5 \mathrm{~kg} / \mathrm{m}^{2}$, age $\geq 40$ years, and having delivery assisted by nonhealth professional were the independent determinants of POP. Therefore, skilled delivery, further promoting family planning and girls' education, early pelvic floor assessment, and counseling on avoidance of carrying heavy objects are recommended.

Keywords: pelvic organ, prolapse, determinant, case-control, counseling, education

\section{Introduction}

POP is the descent of pelvic organs into the vagina, and in these cases women can feel different prolapse symptoms like "something coming down", and other urinary, bowel, and sexual symptoms. ${ }^{1,2}$ POP severely affects women's quality of life in several ways. It has socioeconomic and health consequences, affecting overall health and sexual function. ${ }^{3}$ It has been a major gynecologic problem in developed and developing nations. ${ }^{4}$ However, women in developing countries are affected disproportionally. ${ }^{5,6}$ In the United States, different types of POP, such as uterine prolapse, cystocele, and rectocele, are prevalent. ${ }^{7}$ Due to the multitude of factors associated with socioeconomic and institutional factors, the prevalence of POP has been significant in developing countries. ${ }^{4,8-10}$ 
In Ghana and Dabat (Ethiopia), a significant proportion of women had stage II-IV anatomical pelvic organ prolapse. ${ }^{4,8}$ Similarly, studies in Nigeria ${ }^{10}$ and Nepal ${ }^{11}$ showed that different forms of POP have been affecting women's health and quality of life alarmingly. ${ }^{12}$ Women with POP have been suffering from significant social problems such as sexual relationships problems, functional impairment, depression, and poor quality of life. ${ }^{13-17}$ In Ethiopia, gynecological problems are important health problems affecting maternal health outcomes and women's productivity. ${ }^{18}$ In clinical setups, POP accounted for $40.7 \%$ of major gynecological operations. ${ }^{19}$ In Tikur Anbesa, POP was the major (41.1\%) identified reason for hysterectomy, followed by leiomyoma (23\%). ${ }^{20}$ Studies showed that obstetric characteristics (parity and gravidity and delivery position) ${ }^{21}$ and sociodemographic factors (educational status, occupational status, and early return to work $)^{21}$ were found to be significant risk factors for POP.

Though the problem is eminent, the true incidence and risk factors associated with POP have been poorly understood. This might be due to the most private and asymptomatic nature of the illness making POP the "hidden epidemic". ${ }^{22}$ In this regard, the Ethiopian government has not developed a separate strategy to prevent and/or manage POP in its health sector/system. Although different studies have identified different types and levels of interventions, ${ }^{1,2,5}$ there has been paucity of locally generated evidence on the magnitude and determinants of POP to design appropriate prevention strategies.

Therefore, the objective of this study was to identify the determinants or factors of POP among gynecologic patients in Bahir Dar, North West Ethiopia.

\section{Methods}

\section{Study design and setting}

This was an unmatched case-control study conducted from July to October 2014 in two hospitals (Felege Hiwot Referral Hospital and GAMBY Teaching Hospital) at Bahir Dar city (565 km North West of Addis Ababa). These hospitals were selected because they provide POP surgical intervention. Gynecologic patients (age $>18$ years) diagnosed with stage III or IV POP were taken as cases, while those clients declared free of POP were taken as controls. A total of 370 (124 cases and 246 controls; $1: 2$ case to control ratio) participants were included in the study. All cases in the two hospitals were included, and controls for each case were selected using systematic random sampling technique.

\section{Measurement}

In this study, clients free of POP were taken as controls; those with stage I or II were excluded from the study, and those with stages III or IV were taken as cases. POP was evaluated and described using a standardized Pelvic Organ Prolapse Quantitative Examination tool. ${ }^{23,24}$ In this technique, the hymen ring (remnant) is used as a reference point and is called a "half-way system". Therefore, all the measurements were taken in a semiupright position and interpreted as: stage-0 "no prolapse"; stage I is when the most distal portion (leading surface) of the prolapse is $>1 \mathrm{~cm}$ above the level of the hymen $(<-1 \mathrm{~cm})$; stage II is when the most distal portion (leading edge) of the prolapse is $\leq 1 \mathrm{~cm}$ proximal to or extends $1 \mathrm{~cm}$ through the plane of hymen $(\geq-1 \mathrm{~cm}$, but $\leq+1 \mathrm{~cm}$ ); stage III is when the most distal portion of the prolapse is $>1 \mathrm{~cm}$ below hymen but no further than $2 \mathrm{~cm}$ less than the TVL (there is no complete vaginal eversion); and stage IV is when there is complete eversion of the total length of the pelvic organ, meaning the pelvic organ protrudes at least the total vaginal length minus $2 \mathrm{~cm}$ beyond the hymen. ${ }^{23,24}$ In this measurement, negative number referees were taken as centimeters above or proximal to the hymen, while positive number referees were taken as centimeters below or distal to the hymen. ${ }^{24}$

\section{Data management and analysis}

Data were collected using structured questionnaire developed from existing literature. ${ }^{14,25}$ Trained midwives and nurses collected the data using the Amharic (local langue) version questionnaire under strict daily supervision. Detailed obstetrics and gynecologic history was taken and vaginal examinations were performed by trained physicians. Questionnaires were coded and entered into the SPSS $^{26}$ version 20 for analysis. Descriptive, bivariate, and multivariable logistic regression analyses were carried out. After the descriptive statistical analysis, bivariate logistic regression analysis was performed. Variable showing statistically significant association at the bivariate logistic regression analysis (at $P<0.05$ ) were selected and entered to the multivariable logistic regression analysis. Statistical difference was considered at $P<0.05$, and the strength of association was assessed by OR and respective CIs.

\section{Results \\ Sociodemographic characteristics}

Out of the total sample size, 349 (124 cases and 225 controls) respondents were participated. The total response rate was $94.3 \%$ (349/370) (100\% for cases and $91.5 \%$ for controls). The mean ( \pm standard deviation $[\mathrm{SD}])$ age of 
the respondents' was 43 years \pm 12 SD (46 years for cases and 39 years for controls). Majority of the cases (89.5\%) and controls (76\%) were Orthodox Christian by religion. Majority of cases ( $n=111$ [89.5\%]) were rural residents. One hundred ninety nine (96\%) women from cases did not have formal education. Majority of women were unemployed for both cases and controls: 119 (96\%) and 166 (73.8\%), respectively (Table 1).

\section{Obstetric and other characteristics}

One hundred five $(84.7 \%)$ of the cases had more than four deliveries, whereas only $26.7 \%$ of controls had $\geq 4$ deliveries. Majority $(n=103$ [83.3\%]) of women who had POP gave their last birth at home; while only 87 (38.7\%) women in the control group delivered their last child at home. A majority $(n=114[91.9 \%])$ of the cases had their first child at the age of $\leq 20$ years. Chronic cough was observed among 218 (96.9\%) controls and $114(91.9 \%)$ cases. Ninety-three (75\%) cases and $90(40 \%)$ controls had history of carrying heavy objects (Table 2).

\section{Factors associated with POP}

In our study, sociodemographic variables (such as maternal age, residence, formal education, and occupation), obstetric factors (ie, number of pregnancy, number of vaginal births/ parity, place of delivery, type of delivery assistant, position

Table I Sociodemographic characteristics of respondents in Felege Hiwot Referral Hospital and GAMBY Teaching Hospital, Bahir Dar city, 2014

\begin{tabular}{|c|c|c|}
\hline $\begin{array}{l}\text { Characteristics of } \\
\text { respondents }(n=349)\end{array}$ & $\begin{array}{l}\text { Cases } \\
\mathrm{n}=124(\%)\end{array}$ & $\begin{array}{l}\text { Controls } \\
n=225(\%)\end{array}$ \\
\hline \multicolumn{3}{|l|}{ Age } \\
\hline$<40$ years & $35(28.2)$ & 164 (72.9) \\
\hline$\geq 40$ years & $89(71.8)$ & $61(27.1)$ \\
\hline \multicolumn{3}{|l|}{ Residence } \\
\hline Urban & $13(10.5)$ & $103(45.8)$ \\
\hline Rural & III (89.5) & $122(54.2)$ \\
\hline \multicolumn{3}{|l|}{ Religion } \\
\hline Orthodox & III (89.5) & I7I (76.0) \\
\hline Muslim & $9(7.3)$ & $38(16.9)$ \\
\hline Protestant & $4(3.2)$ & $16(7.1)$ \\
\hline \multicolumn{3}{|l|}{ Marital status } \\
\hline Single & $63(50.8)$ & $53(23.6)$ \\
\hline Married & $61(49.2)$ & $172(76.4)$ \\
\hline \multicolumn{3}{|l|}{ Formal education } \\
\hline Yes & $5(4.0)$ & $93(41.3)$ \\
\hline No & $119(96)$ & I 32 (58.7) \\
\hline \multicolumn{3}{|l|}{ Occupational status } \\
\hline Employed & $5(4.0)$ & $59(26.2)$ \\
\hline Unemployed & $119(96.0)$ & $166(73.8)$ \\
\hline
\end{tabular}

Table 2 Obstetric and related characteristics of cases and controls in Felege Hiwot Referral Hospital and GAMBY Teaching Hospital, Bahir Dar city, 2014

\begin{tabular}{|c|c|c|}
\hline $\begin{array}{l}\text { Characteristics of } \\
\text { respondents }(n=329)\end{array}$ & $\begin{array}{l}\text { Cases } \\
n=\mid 24(\%)\end{array}$ & $\begin{array}{l}\text { Controls } \\
\mathrm{n}=225(\%)\end{array}$ \\
\hline \multicolumn{3}{|l|}{ Number of pregnancy } \\
\hline$<4$ & 14 (I I.3) & $150(66.7)$ \\
\hline$\geq 4$ & $110(88.7)$ & $75(33.3)$ \\
\hline \multicolumn{3}{|l|}{ Number of parity } \\
\hline$<4$ & $19(15.3)$ & $165(73.3)$ \\
\hline$\geq 4$ & $105(84.7)$ & $60(26.7)$ \\
\hline \multicolumn{3}{|c|}{ Place of delivery (for the last birth) } \\
\hline Health institution & $21(16.9)$ & | 38 (6I.3) \\
\hline Home & $103(83.3)$ & $87(38.7)$ \\
\hline \multicolumn{3}{|l|}{ Delivery assisted by } \\
\hline Health professional & $18(14.5)$ & 137 (60.9) \\
\hline Nonhealth professional & $106(85.5)$ & $88(39.1)$ \\
\hline \multicolumn{3}{|l|}{ Return to work after delivery } \\
\hline$\geq 42$ days & $7(5.6)$ & $69(30.7)$ \\
\hline$<42$ days & $117(94.4)$ & $156(69.3)$ \\
\hline \multicolumn{3}{|c|}{ Position during labor (for the last birth) } \\
\hline Lying & $45(36.3)$ & $162(72)$ \\
\hline Knee to chest & $79(63.8)$ & $63(28)$ \\
\hline \multicolumn{3}{|l|}{ Delivery interval } \\
\hline$>2$ years & $85(68.5)$ & $152(73.1)$ \\
\hline$\leq 2$ years & $39(31.5)$ & $55(26.4)$ \\
\hline \multicolumn{3}{|c|}{ Duration of labor (for the last birth) } \\
\hline$<8$ hours & $63(50.8)$ & $119(52.9)$ \\
\hline$\geq 8$ hours & $61(49.2)$ & $106(47.1)$ \\
\hline \multicolumn{3}{|l|}{ Age at first delivery } \\
\hline$\geq 20$ years & $10(8.1)$ & $79(35.1)$ \\
\hline$<20$ years & 114 (91.9) & $146(64.9)$ \\
\hline \multicolumn{3}{|l|}{ Sphincter damage } \\
\hline No & $110(88.7)$ & $221(98.2)$ \\
\hline Yes & $14(1 \mid .3)$ & $4(1.8)$ \\
\hline \multicolumn{3}{|c|}{ Vaginal tear (for the last birth) } \\
\hline No & $107(86.3)$ & $173(76.9)$ \\
\hline Yes & $17(13.7)$ & $52(23.1)$ \\
\hline \multicolumn{3}{|l|}{ Carry heavy object } \\
\hline No & $31(25)$ & $135(60)$ \\
\hline Yes & $93(75)$ & $90(40)$ \\
\hline \multicolumn{3}{|l|}{ Chronic cough } \\
\hline No & 114 (9l.9) & $218(96.9)$ \\
\hline Yes & $10(8.1)$ & $7(3.1)$ \\
\hline \multicolumn{3}{|l|}{ Family history of POP } \\
\hline No & $96(77.4)$ & $211(93.8)$ \\
\hline Yes & $28(22.6)$ & $14(6.2)$ \\
\hline \multicolumn{3}{|l|}{ BMI } \\
\hline $18.5-24.9 \mathrm{~kg} / \mathrm{m}^{2}$ & $96(77.4)$ & $189(84.0)$ \\
\hline$<18.5 \mathrm{~kg} / \mathrm{m}^{2}$ & $23(18.5)$ & $14(6.2)$ \\
\hline$\geq 25 \mathrm{~kg} / \mathrm{m}^{2}$ & $5(4.0)$ & $22(9.8)$ \\
\hline
\end{tabular}

Abbreviations: POP, pelvic organ prolapse; BMI, body mass index.

during labor, sphincter damage), history of carrying heavy objects, history of chronic cough, family history of POP, and BMI were the identified risks for POP.

Multivariable logistic regression analysis (with entry requirement $P<0.2$ ) showed that maternal age ( $>40$ years) 
(adjusted OR [AOR] =3.0 [95\% CI: 1.59-5.89]), sphincter damage (AOR $=8.1$ [95\% CI: 1.67-39.7]), family history of POP $(\mathrm{AOR}=4.9$ [95\% CI: 1.94-12.63]), parity $(\mathrm{AOR}=4.5$ [95\% CI: 2.26-9.10]), nonattendance of formal education (AOR $=4.3$ [95\% CI: $1.25-14.8]$ ), history of carrying heavy objects (AOR $=3.1$ [95\% CI: $1.56-6.30]$ ), BMI of $<18.5 \mathrm{~kg} / \mathrm{m}^{2}$ (AOR $=3.1$ [95\% CI: 1.22-7.82]), and delivery assisted by nonhealth professionals (AOR $=2.6$ [95\% CI: 1.24-5.56]) were statistically associated with POP (Table 3).

\section{Discussion}

Different studies, ${ }^{4,9,27-31}$ including in Ethiopia ${ }^{12,19}$ showed that multiparous women have increased risk of POP. Similarly, in our study, multipara women (parity $\geq 4$ ) were 4.5 times more likely to have POP compared with their counterparts. Although multiple pregnancy was not statistically significant in our study, other studies in Ethiopia, Ghana, and Nepal reported that multiple pregnancy/gravidity is a predictor of POP. ${ }^{32,33}$ This might be due to the fact that repeated pregnancy and birth damages sphincter muscles and ligaments, which sometimes never fully regain its strength and elasticity. This was also observed in our study, as mothers who had sphincter damage were eight times more likely to have POP compared to mothers who did not have sphincter damage. A study conducted in Nepal similarly indicated that sphincter damage is a risk factor for POP. ${ }^{11}$ This is in line with the scientifically established fact that sphincter muscles, together with their surrounding tissues, are responsible for keeping/supporting all of the pelvic organs. ${ }^{34-40}$

On the other hand, family history was found to be a predictor for POP. In this regard, women with positive POP family history were five times more likely to have had POP compared with their counter parts. This finding is consistent with other studies which reported that family history is an important risk factor for POP..$^{25,29,41}$

In our study, educational status showed a statistically significant association with POP, with women who did not attend formal education being 4.3 times more likely to have POP compared with the educated women. Similarly, studies from Nepal ${ }^{42}$ and $\mathrm{Al}$ Ain (UAE) ${ }^{43}$ indicated that illiterate women were more likely to be affected by POP. Higher risk of POP among illiterate women might be due to higher proportion of delivery at home (83.3\%), possibly without the attendance of skilled health professionals.

Studies suggest that women engaged in farming, carrying and marketing of agricultural products, wood collection, fetching water from a distant area are more likely to have POP ${ }^{19}$ In a similar fashion, although rural residence is not statistically associated with POP, in our study, women who had history of carrying heavy objects had increased POP risk compared with their counter parts. This might be due to the reason that in our study $89.5 \%$ of women with POP were rural inhabitants, whose daily activities included carrying and moving heavy household and agricultural loads. Hence, it is possible to justify that the association of farming activity of rural women and the risk of POP was indirectly through carrying heavy objects, a factor which is also common in other regions of Ethiopia and other developing nations. ${ }^{8,12,19}$

Although obesity (BMI $\geq 25 \mathrm{~kg} / \mathrm{m}^{2}$ ) could increase the risk of $\mathrm{POP},{ }^{9,42}$ this study found a contrary finding that being underweight (BMI $<18.5 \mathrm{~kg} / \mathrm{m}^{2}$ ) increases the risk of POP threefold. Different studies reported that the risk of POP increases with age..$^{12,19,30,33,44}$ Similarly, in our study, women aged $\geq 40$ years were about three times more likely to have had POP compared to women aged $<40$ years old. A study conducted in Jimma, Ethiopia, documented such a consistent finding. ${ }^{19}$ This might be due to the fact that the risk of POP increases with age. ${ }^{45}$ However, a study conducted in Gondar Dabat district, Ethiopia, reported a contradictory finding. ${ }^{8}$

In our study, women assisted by nonhealth professionals during delivery were 2.6 times more likely to have POP. This was consistent with earlier studies from Nepal and India..$^{27,31}$

This study did not assess some of risks for POP such as mode of delivery for the previous vaginal birth and history of instrument-assisted delivery. This study could not match cases and controls by age, which might be an important contributor in the occurrence of POP. Additionally, since this was a hospital-based study, it did not allow for the inclusion of a specific population or community at large. Recall bias also might have been introduced as the respondents were asked questions about some of their previous health-related events. Therefore, this study needs cautious interpretation to draw conclusions.

\section{Conclusion}

In conclusion, this study revealed that multifaceted factors such as sphincter damage, family history of POP, being uneducated, having $\geq 4$ vaginal deliveries, carrying heavy objects, BMI $<18.5 \mathrm{~kg} / \mathrm{m}^{2}$, age $\geq 40$ years, and delivery assisted by nonhealth professional are the determinants of POP. Delivery at health institutions, assistance by health professional during deliver, prevention of maternal malnutrition, empowerment of women (through education) to utilize family planning in turn to prevent too late and too many pregnancies, counseling to avoid carrying heavy objects, early pelvic floor assessment/ screening for potential sphincter damage, and studies over large geographical areas are recommended. 
Table 3 Factors associated with POP in Felege Hiwot Referral Hospital and GAMBY Teaching Hospital, Bahir Dar city, 2014

\begin{tabular}{|c|c|c|c|c|}
\hline Characteristics $(n=349)$ & Cases $n=124(\%)$ & Controls $n=225(\%)$ & Crude OR $(95 \% \mathrm{Cl})$ & AOR $(95 \% \mathrm{Cl})$ \\
\hline \multicolumn{5}{|l|}{ Age } \\
\hline$\geq 40$ years & 89 (71.8) & $61(27.1)$ & $6.8(4.19-11.15)^{*}$ & $3.0(1.59-5.89)^{*}$ \\
\hline$<40$ years & $35(28.2)$ & I64 (72.9) & 1 & 1 \\
\hline \multicolumn{5}{|l|}{ Residence } \\
\hline Rural & III (89.5) & $122(54.2)$ & $7.2(3.83-13.55)^{*}$ & - \\
\hline Urban & $13(10.5)$ & $103(45.8)$ & 1 & \\
\hline \multicolumn{5}{|l|}{ Formal education } \\
\hline No & $119(96)$ & $132(58.7)$ & $16.7(6.59-42.64)^{*}$ & $4.3(1.25-14.87)^{*}$ \\
\hline Yes & $5(4)$ & $93(41.3)$ & 1 & I \\
\hline \multicolumn{5}{|l|}{ Occupational status } \\
\hline Unemployed & $119(96)$ & $166(73.8)$ & $8.4(3.29-21.71) *$ & - \\
\hline Employed & $5(4)$ & $59(26.2)$ & 1 & \\
\hline \multicolumn{5}{|l|}{ Pregnancy } \\
\hline$\geq 4$ & II 0 (88.7) & $75(33.3)$ & I 5.7 (8.44-29.25)* & - \\
\hline$<4$ & I4 (II.3) & $150(66.7)$ & 1 & \\
\hline \multicolumn{5}{|l|}{ Parity/delivery } \\
\hline$\geq 4$ & $105(84.7)$ & $60(26.7)$ & $15.2(8.58-26.90)^{*}$ & $4.5(2.26-9.10)^{*}$ \\
\hline$<4$ & $19(15.3)$ & $165(73.3)$ & 1 & I \\
\hline \multicolumn{5}{|c|}{ Place of delivery (for the last birth) } \\
\hline Home & $103(83.3)$ & $87(38.7)$ & $7.7(4.53-13.35)^{*}$ & - \\
\hline Health institution & $21(16.9)$ & $138(6 \mid .3)$ & 1 & \\
\hline \multicolumn{5}{|l|}{ Delivery assisted by } \\
\hline Nonhealth professional & $106(85.5)$ & $88(39.1)$ & $9.2(5.20-16.16)^{*}$ & $2.6(1.24-5.56)^{*}$ \\
\hline Health professional & $18(14.5)$ & $137(60.9)$ & 1 & $\mathrm{I}$ \\
\hline \multicolumn{5}{|l|}{ Return to work after delivery } \\
\hline$<42$ days & $117(94.4)$ & $156(69.3)$ & $7.3(3.27-16.67)^{*}$ & - \\
\hline$\geq 42$ days & $7(5.6)$ & $69(30.7)$ & I & \\
\hline \multicolumn{5}{|l|}{ Position during labor } \\
\hline Knee to chest & $79(63.8)$ & $63(28)$ & $4.5(2.82-7.20)^{*}$ & - \\
\hline Lying & $45(36.3)$ & $162(72)$ & 1 & \\
\hline \multicolumn{5}{|l|}{ Delivery interval } \\
\hline$\leq 2$ years & $39(31.5)$ & $55(26.4)$ & $1.2(0.78-2.07)$ & - \\
\hline$>2$ years & $85(68.5)$ & $152(73.1)$ & 1 & \\
\hline \multicolumn{5}{|c|}{ Duration of labor (for the last birth) } \\
\hline$\geq 8$ hours & $61(49.2)$ & $106(47.1)$ & $1.0(0.70-1.68)$ & - \\
\hline$<8$ hours & $63(50.8)$ & $119(52.9)$ & 1 & \\
\hline \multicolumn{5}{|l|}{ Age at first delivery } \\
\hline$<20$ years & II4 (9I.9) & $146(64.9)$ & $6.1(3.05-12.44)^{*}$ & - \\
\hline$\geq 20$ years & $10(8.1)$ & $79(35.1)$ & 1 & \\
\hline \multicolumn{5}{|l|}{ Sphincter damage } \\
\hline Yes & $14(\mid \mathrm{I} .3)$ & $4(1.8)$ & $7.0(2.26-21.86)^{*}$ & $8.1(1.67-39.70)^{*}$ \\
\hline No & $110(88.7)$ & $221(98.2)$ & $\mathrm{I}$ & $\mathrm{I}$ \\
\hline \multicolumn{5}{|l|}{ Vaginal tear } \\
\hline Yes & $17(13.7)$ & $52(23.1)$ & $0.53(0.29-0.96)^{*}$ & - \\
\hline No & $107(86.3)$ & $173(76.9)$ & $\mathrm{I}$ & \\
\hline \multicolumn{5}{|l|}{ Carry heavy object } \\
\hline Yes & $93(75.0)$ & $90(40.0)$ & $4.5(2.767-7.3 \mid 7)^{*}$ & $3.1(1.56-6.30)^{*}$ \\
\hline No & $31(25.0)$ & $135(60.0)$ & 1 & I \\
\hline \multicolumn{5}{|l|}{ Chronic cough } \\
\hline Yes & $10(8.1)$ & $7(3.1)$ & $2.7(1.01-7.36)^{*}$ & - \\
\hline No & II4 (91.9) & $218(96.9)$ & 1 & \\
\hline Family history of POP & & & & \\
\hline Yes & $28(22.6)$ & $14(6.2)$ & $4.4(2.21-8.72)^{*}$ & $4.9(1.94-12.63)^{*}$ \\
\hline No & $96(77.4)$ & $211(93.8)$ & 1 & 1 \\
\hline BMI & & & & \\
\hline$<18.5 \mathrm{~kg} / \mathrm{m}^{2}$ & $23(18.5)$ & $14(6.2)$ & $3.2(1.59-6.56)$ & $3.1(1.22-7.82)^{*}$ \\
\hline $18.5-24.9 \mathrm{~kg} / \mathrm{m}^{2}$ & $96(77.4)$ & $189(84.0)$ & 1 & I \\
\hline$\geq 25 \mathrm{~kg} / \mathrm{m}^{2}$ & $5(4.0)$ & $22(9.8)$ & $0.4(0.16-1.21)$ & $0.5(0.14-2.13)$ \\
\hline
\end{tabular}

Note: *Statistically significant at $P<0.05$ (two-tailed).

Abbreviations: AOR, adjusted odds ratio; OR, odds ratio; POP, pelvic organ prolapse; BMI, body mass index. 


\section{Ethical approval and consent to participate \\ Ethical consideration}

Ethical clearance was obtained from the ethical review committee of Bahir Dar University, College of Medicine and Health Sciences. Permission letter was obtained from Amhara National Regional State Health Bureau, and respective hospitals. Written informed consent was secured from study participants. Strict confidentiality and client privacy was maintained given that the standard medical examination/ practice has been done.

\section{Availability of data and material}

All the data related to this article and its conclusion are available as tables.

\section{Acknowledgments}

The authors would like to thank Bahir Dar University for its technical support, study participants, data collectors, and physicians without whom this study could not have been realized. Special thanks goes to Dr Ayenew Belay for providing technical support and facilitation.

\section{Author contributions}

AA conceived the study and analyzed the data. TS interpreted the result and drafted the manuscript. TS and EA produced and reviewed the manuscript critically. All authors contributed toward data analysis, drafting and critically revising the paper and agree to be accountable for all aspects of the work.

\section{Disclosure}

The authors report no conflicts of interest in this work.

\section{References}

1. Jelovsek J, Maher C, Barber MD. Pelvic organ prolapse. Lancet. 2007;369: 1027-1038.

2. Vimplis S, Hooper P. Assessment and management of pelvic organ prolapse. Curr Obstet Gynaecol. 2005;15:387-393.

3. Lince SL, van Kempen LC, Vierhout ME, Kluivers KB. A systematic review of clinical studies on hereditary factors in pelvic organ prolapse. Int Urogynecol J. 2012;23(10):1327-1336.

4. Wusu-Ansah OK, Opare-Addo HS. Pelvic organ prolapse in rural Ghana. Int J Gynecol Obstet. 2008;103:121-124.

5. Luft J. Pelvic organ prolapse: current state of knowledge about this common condition. J Nurse Pract. 2006;2:171-177.

6. Popovic JR, Kozak LJ. National hospital discharge survey: annual summary, 1998. Vital Health Stat 13. 2000;148:1-194.

7. Drutz HP, Alarab M. Pelvic organ prolapse: demographics and future growth prospects. Int Urogynecol J. 2006;17:S6-S9.

8. Berihun MZ, Adefris M, Rortveit G, et al. Pelvic floor disorders among women in Dabat district, northwest Ethiopia: a pilot study. Int Urogynecol J. 2013;24(7):1135-1143.

9. Lien YS, Chen GD, Ng SC. Prevalence of and risk factors for pelvic organ prolapse and lower urinary tract symptoms among women in rural Nepal. Int J Gynecol Obstet. 2012;119:185-188.
10. Okonkwo JE, Obionu CO, Obiechina NJ. Factors contributing to urinary incontinence and pelvic prolapse in Nigeria. Int J Gynecol Obstet. 2001;74(3):301-303.

11. Thapa S, Angdembe M, Chauhan D, Joshi R. Determinants of pelvic organ prolapse among the women of the western part of Nepal: a casecontrol study. J Obstet Gynaecol Res. 2014;40(2):515-520.

12. Lukman Y. Utero-vaginal prolapse: a rural disability of the young. East Afr Med J. 1995;72(1):2-9.

13. Berihun MZ, Awoke AT, Adefris WM, Azale BT, Awoke AA. Depression among women with obstetric fistula, and pelvic organ prolapse in northwest Ethiopia. BMC Psychiatry. 2013;13:236.

14. Kaplan PB, Sut N, Sut HK. Validation, cultural adaptation and responsiveness of two pelvic-floor-specific quality-of-life questionnaires, PFDI-20 and PFIQ-7, in a Turkish population. Eur J Obstet Gynecol Reprod Biol. 2012;162(2):229-233.

15. Shaabana MM, Abdelwahab HA, Ahmed MR, Shalaby E. Assessment of female sexual function among women with pelvic organ prolapse or urinary incontinence via an Arabic validated short-form sexual questionnaire. Int J Gynecol Obstet. 2014;124(1):24-26.

16. Su TH, Lau HH. Validation of a Chinese version of the short form of the pelvic organ prolapse/urinary incontinence sexual questionnaire. J Sex Med. 2010;7(12):3940-3945.

17. Twiss C, Triaca V, Bergman J, Rodríguez LV. The epidemiology, social burden, and genetics of pelvic organ prolapse. Curr Bladder Dysfunct Rep. 2008;3:90.

18. Berhane Y, Gossaye Y, Emmelin M, Hogberg U. Women's health in a rural setting in societal transitionin Ethiopia. Soc Sci Med. 2001;53: $1525-1539$.

19. Menur A, Hailemariam S. Pelvic organ prolapse in Jimma University specialized hospital, South West Ethiopia. Ethiop J Health Sci. 2012; 22(2):85-92.

20. Gaym A. Elective hysterectomy at TikurAnbessa Teaching Hospital, Addis Ababa. Ethiop Med J. 2002;40(3):217-226.

21. Gautam S, Adhikari RK, Dangol A. Associated factors for uterine prolapse. J Nepal Health Res Counc. 2012;10(1):1-4.

22. Cordozo L. Prolapse. In: Whitfield CR, editor. Dewhurse's Textbook of Obstetrics and Gynaecology for Postgraduates. Oxford, UK: Blackwell Science; 1995:642-652 (Cross reference).

23. Bump RC, Mattiasson A, Bo K, et al. The standardization of terminology of female pelvic organ prolapse and pelvic floor dysfunction. Am J Obstet Gynecol. 1996;175(1):10-17.

24. Chen G, Soo-Cheen N. Updated definition of female pelvic organ prolapse. Incont Pelvic Floor Dysfunct. 2007;1(4):121-124.

25. Alcalay M, Stav K, Eisenberg VH. Family history associated with pelvic organ prolapse in young women. Int Urogynecol J. 2015;26(12): 1773-1776. Epub July 15, 2015.

26. SPSS. PASW STATISTICS version 18. Chicago, IL: SPSS Inc; 2009.

27. Baruwal A. Knowledge, Attitude and Preventive Measures Amongst the Married Women of Reproductive Age Towards Uterine Prolapse in the 8 VDCS of Surkhet District, Nepal [master's thesis]. Bangkok: College of Public Health Sciences, Chulalongkorn Univeristy; 2010.

28. Handa VL, Garrett E, Hendrix S, Gold E, Robbins J. Progression and remission of pelvic organ prolapse: a longitudinal study of menopausal women. Am J Obstet Gynecol. 2004;190(1):27-32.

29. Hendrix SL, Clark A, Nygaard I, Aragaki A, Barnabei V, McTiernan A. Pelvic organ prolapse in the Women's Health Initiative: gravity and gravidity. Am J Obstet Gynecol. 2002;186:1160-1166.

30. Kim CM, Jeon MJ, Chung DJ, Kim SK, Kim JW, Bai SW. Risk factors for pelvic organ prolapse. Int J Gynecol Obstet. 2007;98(3):248-251.

31. Patil P, Patil A. Evaluation of pelvic organ prolapse in indian females. J Evol Med Dent Sci. 2013;12(40):7612-7620.

32. Swift S, Woodman P, O'Boyle A, et al. Pelvic Organ Support Study (POSST): the distribution, clinical definition, and epidemiologic condition of pelvic organ support defects. Am J Obstet Gynecol. 2005; 192(3):795-806.

33. Swift SE, Pound T, Dias JK. Case-control study of etiologic factors in the development of severe pelvic organ prolapse. Int Urogynecol J Pelvic Floor Dysfunct. 2001;12(3):187-192. 
34. Bozkurt M, Yumru AE, Sahin L. Pelvic floor dysfunction, and effects of pregnancy and mode of delivery on pelvic floor. Taiwan J Obstet Gynecol. 2014;53(4)452-458.

35. Dietz HP. Pelvic floor trauma in childbirth. Aust NZJ Obstet Gynaecol. 2013;53(3):220-230.

36. Groenendijk AG, Birnie E, Boeckxstaens GE, et al. Anorectal function testing and anal endosonography in the diagnostic work-up of patients with primary pelvic organ prolapse. Gynecol Obstet Invest. 2009;67(3):187-194.

37. Hiltunen KM. Clinical and manometric evaluation of anal sphincter function in patients with rectal prolapse. Am J Surg. 1986;151(4): 489-492.

38. Hosli I. Beckenboden in der Schwangerschaft und unter der Geburt. [Influence of pregnancy and delivery to the pelvic floor]. Ther Umsch. 2010;67(1):11-18. German.

39. Matarazzo MG, Cianci S, Rampello L, et al. Urethral sphincter innervation and clitoral blood flow after the transobturator (TOT) approach. Int Urogynecol J. 2013;24(4):621-625.
40. Thapa S, Angdembe M, Chauhan D, et al. Determinants of pelvic organ prolapse among the women of the western part of Nepal: a case-control study. J Obstet Gynaecol Res. 2014;40(2):515-520.

41. Mothes AR, Radosa MP, Altendorf-Hofmann A, Runnebaum IB. Risk index for pelvic organ prolapse based on established individual risk factors. Arch Gynecol Obstet. 2016;293(3):617-624.

42. Pradhan S. Unheeded Agonies: a study on uterine prolapse prevalence and it's causes in Siraha and Saptari districts. Kathmandu, Nepal: Women's Reproductive Rights programe (WRRP), Center for AgroEcology and Development (CAED); 2007.

43. Elbiss HM, Osman N, Hammad FT. Prevalence, risk factors and severity of symptoms of pelvic organ prolapse among Emirati women. $B M C$ Urol. 2015;15:66.

44. Swift SE, Tate SB, Nicholas J. Correlation of symptoms with degree of pelvic organ support in a general population of women: what is pelvic organ prolapse? Am J Obstet Gynecol. 2003;189(2):372-377.

45. Shek KL, Dietz HP. Assessment of pelvic organ prolapse: a review. Ultrasound Obstet Gynecol. Epub 2016 Feb 11.
International Journal of Women's Health

\section{Publish your work in this journal}

The International Journal of Women's Health is an international, peerreviewed open-access journal publishing original research, reports, editorials, reviews and commentaries on all aspects of women's healthcare including gynecology, obstetrics, and breast cancer. The manuscript management system is completely online and includes

\section{Dovepress}

a very quick and fair peer-review system, which is all easy to use. Visit http://www.dovepress.com/testimonials.php to read real quotes from published authors.

\footnotetext{
Submit your manuscript here: http://www.dovepress.com/international-journal-of-womens-health-journal
} 